University of South Carolina

Scholar Commons

Faculty Publications

Information Science, School of

2008

Credibility on the internet: shifting from authority to reliability

R. David Lankes

University of South Carolina - Columbia, rdlankes@gmail.com

Follow this and additional works at: https://scholarcommons.sc.edu/libsci_facpub

Part of the Library and Information Science Commons

Publication Info

Published in Journal of Documentation, Volume 64, Issue 5, 2008, pages 667-686.

Emerald Group Publishing Limited

This Article is brought to you by the Information Science, School of at Scholar Commons. It has been accepted for inclusion in Faculty Publications by an authorized administrator of Scholar Commons. For more information, please contact digres@mailbox.sc.edu. 


\section{Credibility on the internet: shifting from authority to reliability}

Credibility on the internet

667

\author{
R. David Lankes
}

School of Information Studies, Syracuse University, Syracuse, New York, USA

\begin{abstract}
Purpose - This paper seeks to understand how users determine credibility in the internet environment from a conceptual level and the implications of these new methods of credibility determination on internet tools (primarily software) and services.

Design/methodology/approach - The author first examines the underlying reasons for increased dependence on the internet for information, using electronic commerce as a starting point. The central concept of "information self-sufficiency" is introduced and then examined through the lens of the internet and conversation theory.

Findings - The author finds that users are shifting from more traditional "authority" methods of credibility determination, where users cede determinations to trusted third parties, to a "reliability" approach where users seek commonalities and coherence among multiple information sources. This has led to an increased pressure for participation and openness at all levels of the internet.

Research limitations/implications - Studies on users and credibility must better account for often invisible technical factors.

Practical implications - Libraries must take into account a greater need for participation and technical fluency when dealing with patrons, particularly in information literacy programs and instruction.

Originality/value - This paper presents a large-scale conceptual approach to credibility on the internet. It seeks to inform current approaches to the subject nested in communications and instruction with the unique technical environment of the internet.
\end{abstract}

Keywords Internet, Trust, User studies, Library users, Information science

Paper type Research paper

\section{Introduction: running out of stones}

It has been said that the Stone Age did not end because man ran out of stones. Instead, Stone Age technology was superceded by new tools and capabilities. At some point in history, it simply became more advantageous to adopt new methods and tools rather than trying to solve problems inherent in older methods. Society may soon be at this inflection point in terms of how people identify credible information, abandoning traditional methods of determining credibility for digital tools and new network approaches. Far from being a negative development, these new methods of determining credibility, and the associated tools, will reflect a more distributed and open approach than in the past. Such an approach has important implications for how libraries function, how we educate our youth, how we set policy, and how we build future information systems.

This paper was made possible by grants from the John D. and Catherine T. MacArthur Foundation in connection with its grant making initiative on Digital Media and Learning. For more information on the initiative, visit: www.macfound.org
Received 11 March 2007 Revised 4 September 2007

Accepted 30 September 2007

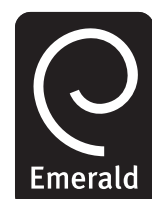

Journal of Documentation

Vol. 64 No. 5, 2008 pp. $667-686$ (C) Emerald Group Publishing Limited 0022-0418 DOI 10.1108/00220410810899709 


\section{JDOC 64,5}

668
This paper will first highlight some reasons why users are moving online and some of the consequences of this move - namely the paradox of "information self-sufficiency." Then, a framework for understanding the implications of information self-sufficiency for learning in a networked digital world will be presented. This background will be used to highlight the often invisible effects technology has upon credibility and information organizations such as libraries. The implications from the model advanced in this paper will then be explored in current and anticipated developments on the internet, including a growing culture of transparency of information based upon network technology. The paper will conclude by discussing how this new transparency, and user's expectations of participation is shifting credibility tools and techniques from traditional authority models to more of a "reliability approach."

\section{May I help you ... online?}

There is little doubt that in the USA and other developed countries, citizens are increasingly relying on the internet to gather information. In total, 73 percent of US adults are internet users, and 42 percent of Americans (approximately 84 million) now have broadband connections at home, up from the 29 percent who reported having broadband at home in January, 2005 (Madden, 2006). This connectivity is actually modest in terms of the percentage of population when compared to Europe and some Asian countries (Wikipedia, 2007). Increasing internet reliance is also evident by the dramatic increase of self-service options available to internet users. Recently, the public is expected to book their own airline tickets, decide on their own retirement plans, even decide between life and death medical treatments with the tools and information available on the web. This shift to digital over physical media is only partly a response to citizen demand for more self-service. Another important factor is increasing economic pressure to minimize cost by eliminating expenses such as printing and customer service personnel. According to the web consulting firm Adaptive Path, "companies pushed labor-intensive tasks out to the customer, and they did so in a way that provided the customers with direct access to and control over information that they care about" (Becker, 2002). The implication is that organizations' move to web self-service is advantageous for commercial organizations, as is evident in substantial cost-savings. For example, ServiceXRG, a market research firm, found that whereas first contact closure cost of phone transactions is $\$ 49.10$, it is $\$ 36.70$ when done via e-mail, and only $\$ 11.60$ via web self-service (Miteko, 2006, p. 39).

However, the advantage to customers is not always so evident. ServiceXRG also found that out of the 60 percent of customers who used web self-service, only 23 percent reported that they found what they were looking for online (Miteko, 2006, p. 38). This means that for every 60 site visitors who choose to use the online self-service channel, only a small minority are able to find content that satisfies their needs, leaving many unsatisfied customers requiring additional support. This example is not atypical (Meuter, 2000, p. 61; van Riel et al., 2001, p. 374). So, while lower cost and greater control for companies and the general public is clearly pushing consumers online, doing so does not necessarily lead to equally satisfactory results for all parties. The question is: in the short term, do the cost savings of online self-support systems outweigh the need by customers and users for control over information?

It is easy to identify examples of bad self-service options. Just about every reader will have a horror story of getting tangled in a phone tree, or diving deep into 
a company web site desperately looking for a phone number to call or person to e-mail. That said, however, there are also plenty of examples where online self-support systems and customer service have been implemented well. Oft-cited examples include Lands' End live chat support service (Abend, 1999), and package tracking through United Parcel Service, Federal Express, and other overnight carriers. Although the examples to this point have focused on commerce, the drive to self-support is just as apparent in nonprofit and governmental sectors. For example, the US National Science Foundation has supported extensive research into "digital government" that seeks to provide support of digital integration over a wide variety of government tasks such as electronic voting, public comments, security and more (Dg.o, 2006). It is also evident in education. Rice (2006) cited "National policy initiatives focused on expanding educational opportunities for all students..., funding shortages, overcrowded brick and mortar facilities ... and exploration of alternative routes for education" as "just a few examples of the forces fueling the expansion of [primary and secondary] distance education programs and schools." Libraries have also spent significant resources to move services such as circulation, reference, and delivery of documents online.

The awkwardness with which some organizations have shifted the responsibility of support from employees to users is understandable. The transition to digital methods of information creation, storage, analysis, and distribution has happened in an astoundingly short period of time. In less than 14 years, the US Federal Government, for example, has gone from mandating executive agency web sites (initially little more than simple online brochures), to requiring electronic voting (Federal Election Commission, 2006), web-based submittals of grant applications (Grants.gov., 2006), and electronic banking transactions. There simply has been too little time and too much change in the internet environment to formalize and codify "good online service." To put it bluntly, what users need in order to take charge of their own online decision making is at best an art, and more often than not, a series of trial and error solutions.

The push and pull of citizenry online has led to a new reality of what the author calls "information self-sufficiency," which affects how products are marketed, how organizations manage information, how courts assess liability, and even how the current and future workforce is trained. Information self-sufficiency is far from an internet-only phenomenon. Anyone who has checked into a flight at the airport knows that the number of touch screens is steeply on the rise, while ticket agents are in steep decline. Libraries now have self check-out kiosks as do grocery and other retail stores. Although information self-sufficiency could be examined in number of ways including economic, political, and even in terms of social and class roles - this paper will concentrate on the effects of information self-sufficiency on credibility. Credibility being defined as "the believability of a source or message, which is made up of two primary dimensions: trustworthiness and expertise" (Flannigan and Metzger, 2007 in MacArthur 2007). Also central to the author's view on credibility is that credibility determinations lies within the individual receiving the information, and it is not an intrinsic quality of the information being transmitted, nor is it conferred by the source of the information (though it may certainly be implied by the source). Credibility is fundamental to the long-term success of self-sufficiency, and by implication, the success of digital media.

While the reality of information self-sufficiency may seem obvious in a world where so many parts of modern life are either online (e.g. online banking, music downloads,

\section{Credibility on the internet}

669 


\section{JDOC 64,5}

670 shopping, medical information, government documents access), or are facilitated by online transactions (e.g. electronic fund transfers, traffic management systems, automated payroll systems), an emphasis on credibility as the crucial factor of success in society's digital migration may not be. Why is credibility essential online and, more to the point, different than in the analog physical world? The answer is based on two truisms of digital networks:

(1) information is necessarily disconnected from any physical origin; and

(2) interactions are all mediated by software tools.

Consider the first truism. When a person buys a book on the internet, they are not basing their buying decision on a single, physical item. They are instead basing the buying decision on information about a book (e.g. its price, author, shipping terms, reviews, etc.). Even if they had previously checked the book out of a library, or paged through it at the local bookstore (where they could have bought the book based on the information it contained and the physical attributes of the book such as whether it is in good shape, etc.), in the online environment they are simply putting in an order for a book based on some proxy, even if that proxy is a digital image of a physical item. This seemingly mundane and obvious fact actually has sweeping implications for credibility on the internet. In particular, for any online transaction that involves delivery of some physical item, a central means of determining credibility - physical examination and testing - is gone (or is at least greatly diminished, since one could always return the book after a physical inspection at the end of the process). No more is it possible to review a signature to make sure it is original. No more is examination of the quality of paper used in a publication practical. No more can one audit a physical inventory. The problems are increasingly found in a library context with the growth of electronic holds.

This separation of the physical from the digitizable leads to some transactions working better in the digital environment than others. For example, while buying books online has become popular, buying homes online is still a rarity. This is due both to the size of the transaction, and also to how much of a physical object's information is intrinsic and how much is extrinsic to itself (Silverstein, 1997). The more mass produced, and therefore standardized an item is, the more information can be "separated out" from that item. In the case of the book, nearly all of the information within the book, the author, the price, the title, even the visual images of the pages themselves, can be recreated accurately in digital form, thus the information is extrinsic to the physical item. In a house, however, the condition of the roof, the true color of the paint, the "feel" of the neighborhood, the creakiness of the floors are all intrinsic qualities that need physical inspection to truly assess. This explains why buying a new car online is not only possible, but is a growing industry. To be sure, it is still a large transaction, but new cars are seen as standard, so a test drive of a car in New York is assumed to be identical to test driving the same make and model in California. Therefore, buying that new car in California does not require a second test drive. The same cannot be said of a house. Houses are unique, and so the information relevant to a buying decision is intrinsic to the house.

Since information is the only evidence available to people when making an online transaction (e.g. buying something, talking to someone, learning about something, etc.), the credibility of that information is essential. Moreover, methods of building trust, and methods to test assertions have changed. For example, if one goes to place a book on hold electronically, that person can no longer test the book to see if it is 
complete and in good condition. They must now trust the online representation of that book. This is the great paradox in information self-sufficiency on the internet: end-users are becoming more responsible for making information determinations, but because they have fewer non-mediated cues (such as a physical item's appearance) to work with, they are becoming more dependent on the information being provided to them by others. So, while a student can now quickly find a used textbook online, they can no longer flip through the pages to make sure it does not (or in some cases does) have hand written notes in the margins. Hence, people are more self-sufficient in

Credibility on the internet

decision making, but also more dependent on the information that others are providing to them. In this way, the digital world increases the importance of credibility, as well as end-users' ability to make credibility judgments. What are the implications of this information self-sufficiency paradox for credibility? The answer may well lay in the internet services users visit and how people go about learning online.

\section{Credibility, conversation, and knowledge}

The Pew Internet \& American Life project did a special report on Web 2.0 (Madden and Fox, 2006) noting a sharp increase in use of "participatory Web." Web 2.0 or the participatory web are simply umbrella terms to capture the rise in truly interactive internet sites that allow users to create, upload, comment upon and share content. The report noted some striking examples of user preferences for participatory applications over more traditional sites such as Wikipedia versus Encarta and Photobucket versus Kodakgallery. The report also found 34 percent of internet users developed and displayed photos online, 30 percent used an online rating service, and 26 percent used the internet to share something the user created. The report concludes "More users want to contribute to and edit entries, and more people are interested in reading them."

What accounts for this drive to social sites? The author argues that it is the very nature of learning, more than simply a person's age or cultural fads that drive users to the social internet. The author's assertions are based upon Pask's (1976) conversation theory. Conversation theory presents a system for understanding how cognitive systems learn and build knowledge. It proposes that learning and knowledge are gained through the interaction of two agents around ideas as they go back and forth describing an idea until they reach agreement. This common agreement can then be used to develop new understandings and new knowledge through a process contemporary learning theorists would call scaffolding: one idea building upon another. Conversation theory is also useful in that it applies to any two cognitive systems. These systems may be two individuals (say a reference librarian and a patron), two organizations (negotiating a set of bibliographic standards), even two societies (debating over the best way to promote literacy). Moreover, knowledge may be gained by having a conversation within one individual or entity, commonly referred to as "metacognition" (or thinking about one's own thinking), a key component of critical thinking and, thus, information literacy (Halpern, 2003).

In light of this theoretical context, the desire on the part of users for social interactions in online learning environments (be they formal or informal) is obvious. As users seek out information they engage in conversations, and the online environment allows for a greater scale and scope of conversants. Furthermore, as they encounter systems for learning in a digital environment, they seek out tools to aid in interactions and conversation. They are seeking out tools that do not simply present information, or third-party 


\section{JDOC 64,5}

672 credibility assessments, but that allow users to participate in the conversation, and therefore the process of knowledge creation and credibility verification.

\section{Credibility dimensions of network technology}

Let us now return to the second truism of working in a digital environment and its implications: all interactions are all mediated by software tools. In a digital environment, users are completely dependent upon software and hardware tools while accessing information and services on their own. Put quite simply, there is no way to be on the internet without some intermediating piece of technology. Be it a web browser, a cell phone, or some other tool, information flowing to and from the internet, as well as information crucial for determining credibility, all flow through seemingly invisible agents of code and silicon. This section of the paper explores both the impact of tools on credibility and how the nature of these tools, particularly software, is changing to better learning in the networked world.

There has been much discussion and research of how the media used to access information can affect the credibility of that information (Fogg, 2002, Chapter 7; Fogg et al., 2003; Metzger et al., 2003a, b; Wathen and Burkell, 2002; Walther et al., 2004). There have also been a number of studies into how the online environment itself affects credibility (Fogg et al., 2001). Together, this work highlights how credibility can be both determined and manipulated by technical elements, such as load time of web pages (Fogg et al., 2000, 2001). Research also points out that, while technology impacts credibility decisions, it is often invisible to the end-user (Ivory and Megraw, 2005). For example, when a teenager is reading about birth control from a web page in a browser, she may think she is making a decision on the credibility of the information based upon the web page, not the browser. While that is certainly partially true, there are two crucial issues here. First, as will be more fully discussed later in this piece, that the teenager is also, often unconsciously, making credibility judgments based upon technical factors (i.e. load time of the page, the ability to display complex graphics, etc) of which she may or may not be consciously aware. Second, there is a great deal of information manipulation that occurs that is never perceptible by the user. Built into the tools themselves are filters, assumptions, biases, and outright distortions that never can be factored into a user's credibility decision (Friedman et al., 2006). This point is completely missed in nearly all examinations of how users make credibility decisions.

In order to highlight the kind of information manipulation that occurs solely in the province of the tools of the digital environment, the Lankes/Eisenberg Architecture (Lankes, 1999) is used. This architecture divides the internet, and by extension, digital networks, into four distinct layers: infrastructure, application, information service, and use. The following sections define these layers, and provide examples of how each level, aside from the use level, can manipulate information in a way that is completely transparently to the user.

\section{Infrastructure layer}

Infrastructure is composed of hardware, such as routers, and protocols, such as the internet's transmission control protocol/internet protocol (TCP/IP) suite used to move bits from one place to another on the internet, and the organizations, such as internet service providers (ISPs) that provide and maintain these mechanisms. This layer is often the most invisible to end-users, yet can have a profound impact on the 
information being provided to users for credibility assessments. Infrastructure providers can easily block traffic to and from certain destinations. What many people do not realize is that such blocked traffic can be made invisible. For example, when a library blocks access to certain web sites they may post a message to a patron's browser stating that the site is blocked. However, there is no technical barrier to that library only providing a "site not found" indication to a user's browser... the same error it would send if the user misspelled a URL. Further, ISPs can block access to any application, disabling software such as instant messaging (IM) at the network layer. The user, not aware of such a block, would only know that their IM program did not connect to a server, and may assume the error lays in the remote server, thus affecting a user's credibility assessment of the remote server, not the infrastructure provider.

\section{Application layer}

Applications on the internet are software that allows information to be exchanged between different actors on the internet. Applications include web browsers and IM clients, as well as high-level protocols such as the HyperText Transfer Protocol that transfers web pages. This broad category covers everything from e-mail applications that automatically mark incoming messages as "junk mail" to the simple mail transfer protocol that enables e-mail over the internet, including spam. Spam filters are excellent examples of technology affecting credibility in a nearly invisible way. Many schools have implemented spam filters based on opaque and often proprietary algorithms at the organization level, discarding numerous e-mail messages before any human eyes ever see them.

\section{Information service layer}

Information services are organizations that use applications and infrastructure to meet users' needs on the internet such as Google, MySapce or a library web site. There are ample studies that look at how information services such as Google skew results in their search engines (for an example and further citations see Choo and Roy, 2004). For example, top results tend towards shopping and technology services in Google (Mowshowitz and Kawaguchi, 2002). Without knowing this, users may assume that top results are the "best" regardless of context.

\section{Use layer}

The use layer is comprised of individuals and groups, such as teachers and patrons, who primarily consume information and seek to meet their own information needs on the internet. Users' means of determining credibility, and their role in affecting credibility is the focus of this paper.

Decisions at each of these layers can affect credibility decisions. The remainder of this paper will focus on tools (primarily software) and how having tools as intermediaries deepens the information self-sufficiency paradox by making users more independent in their information seeking, while simultaneously making them more dependent not only the information they receive, but on the tools they use to access this information.

The fact that technology constraints and decisions that are outside the control of users can alter information before they are able to make credibility decisions has startling implications for libraries and their education efforts. To begin, a common

\section{Credibility on the internet}

673 


\section{JDOC 64,5}

674 strategy to prepare users to make informed credibility decisions is based around educational programs normally under some literacy rubric such as information literacy, digital literacy, or media literacy. These programs present users with various strategies and checklists to determine the quality of information they find via digital media. While this approach makes sense for much of the information a user might access through digital networks, it is not complete. For example, how can one judge the credibility of information for a given URL, when the true URL is masked by inline frames that show content from some third party destination as if it were just a part of a normal page. Although this is a specific technology to the web today, there are sure to be many analogs in future digital technologies. Moreover, there is no amount of literacy instruction that can prepare the average user for the affects of a network infrastructure that they cannot control directly.

To prepare users to make fully informed credibility decisions, they must either become truly fluent in the technology of digital networks, or become aware of potential biases in the network technology itself. Without such technical fluency, users become completely dependent upon, and often unaware of, the stakeholders who control the network's infrastructure, and the policies they create. The question that society must answer is what is the role of users in determining the unavoidable biases and manipulations in the underlying network itself?

Infrastructure as conversation. In many large-scale networks before, and concurrent to, the internet, the issue of users' involvement in the underlying infrastructure would not even be a question. There is nothing inherent in digital networks that make infrastructure participatory. There are many historical examples of large-scale networks that were centrally controlled, where infrastructures were provided to users with little input by those users. Commercial online networks ranging from CompuServe, Prodigy, and America OnLine to not-for-profit Freenets and BitNet networks were black boxes that allowed users to only manipulate pre-made tools. These are historical examples because, even in the case of AOL, these proprietary networks have either been superseded by the internet, or had to radically change their underlying infrastructures to accommodate the internet (Wray and Milmo, 2006).

The internet, on the other hand, was designed to be open, providing only minimal control at the network level, wrapped up in a protocol called TCP/IP. TCP/IP simply breaks data into packets and makes sure these packets get to the proper destination. What these packets contain, what they do, and how they do it is completely ignored. From this very simple packet-switching technology, internet users have built e-mail, the web, IM, and all of the services internet users enjoy today. The point is that these higher-level internet functions are not defined, nor controlled, by the internet itself. Indeed, there is no central authority that controls the internet at all beyond the very basics such as domain name registration and the structure of TCP/IP. Even so-called governing bodies such as the World Wide Web Consortium merely suggest standards that are often embellished, altered or even ignored by software developers (Zeldman, 2003). The internet is, in a very real sense, an agreement, and an ongoing conversation where organizations and individuals agree to share information.

This openness goes a long way to addressing the information self-sufficiency paradox, but only for users with sufficient technology skills and education. Skilled users who are aware of the potential biases and manipulations of the tools they use now have the ability to choose the tools themselves. A person wary of a given web 
browser can use another one, or write their own. If an organization wants to know exactly how its e-mail program is filtering spam, it can now shop multiple filtering packages until it finds the right one; sometimes evaluating the very source code of the

Credibility on the internet

filter. However, simple use skills, that is browsing the web, is insufficient to truly understand the role tools play in the credibility of internet information. If libraries, schools and other institutions prevent users from participating in the underlying infrastructure, they are limiting users' ability to resolve the information self-sufficiency paradox, and therefore limiting users' ability to learn about, and act upon credibility.

This limitation, or rather users' reaction to limiting access to the underlying infrastructure of digital networks can be seen in content filtering put in place at many schools and libraries today. When faced with limited access to the web, many users have begun to document the limitations of the filters themselves. Privacy organizations and civil liberties groups have joined users in challenging the efficacy of filters, and have called for changes (for an example see PEACEFIRE, 2006). Since the infrastructure that these filters are built upon is open, and because the filter is not part of the network, it can be modified or replaced. Suddenly, the invisible nature of the network itself is visible and indeed debatable. Thus, the infrastructure becomes a sort of conversation.

This sort of public cauldron of development has lead to a group of internet users, often tool builders, to view the very process of software development as a means towards credibility. Open source software at its most basic is when the developer of a piece of software makes the underlying source code of the application available to the public. Anyone with sufficient programming skills can take the source code and analyze it, add to it, or incorporate it into another software package. On the internet, this simple concept has been expanded to a more complex, near philosophical approach to any system development (Raymond, 2001). The thinking is that, while anyone with sufficient skill can use open source software, if they improve or expand the original code, they must give the additions back to the open source community.

Open source software and the associated movement, proposes a new concept of credibility in term of tools: credible tools are ones that are built in the open, where a conversation on the merits and structure of infrastructure can be debated and tested. This stands as a stark contrast to more traditional, but equally held models of credible software development. In a more traditional approach to software development, credibility would be defined by the organization that produced the software. This organization would have some standing in the community, good practices, and a proven track record of quality products. Interestingly, this is often proffered in terms of security. A system is "secure" if few have access to its inner workings, and if the few programmers who put it together used a common quality process. The open-source approach takes an opposite track. To be secure, software must be first transparent and then tested. The idea being that, if everyone can see the code, and test it, flaws will be easier to find, and because the process of implementation is tested in public, everyone can trust the product.

This open approach also can be seen in the lens of credibility. Recall the author's definition of credibility, "the believability of a source or message, which is made up of two primary dimensions: trustworthiness and expertise." Open source advocates would claim by being able to dissect and test all aspect of a piece of software, down to the very source code, they can better determine both the trustworthiness of a tool as well as the expertise of the tool's creators (a group which may well include themselves). 


\section{JDOC 64,5}

676
While there is an ongoing debate between these two approaches, with passionate advocates on either side, there is no question that it has changed the shape of tool building on the internet. For example, the internet produced the concept of "open beta" where software products were made available to any internet user to test while still in production. Over time, these beta test processes run longer, sometimes never leaving beta. Even traditional software developers such as Microsoft and Adobe have moved "to enlist a large army of bug testers to help iron out any kinks" (Fott, 2006) in their products.

So, what are the implications for users in the digital environment and credibility in the future? The first is that a user, with enough training, now has equal access to the infrastructure they increasingly depend on. Unlike previous widely adopted technology shifts, such as radio, television, and the phone system, users cannot only adopt technology, they can shape it at its most fundamental levels - infrastructure. Further, with the global nature and low cost of entry of the internet, innovations that are started in one classroom or bedroom can become an internationally adopted standard. Furthermore, with the emphasis of open source on function testing as a means to credibility over origin (e.g. it is not where it came from, it is how it works), anyone, with sufficient technical skills, can enter the infrastructure development arena on an equal footing to established, "credible" organizations. Therefore, any attempt to prepare users for life in the digital world must incorporate some fluency in the basic technologies of the network, and the ethical guidance in how such technologies should be implemented.

\section{The growing culture of transparency}

The concepts of openness, and indeed participation in tools exemplified in the open source movement can also be seen increasingly at the information service level of the Lankes/Eisenberg Architecture, that is, the web sites and remote resources that users access on the web through tools (software). Information services are under increasing pressure to open up their sites and resources to user participation. Information services today increasingly understand the power of participation. Where once services might count hits to a web page, or unique visitors, today whole industries are devoted to analyzing a user's path through a web site to discover what information he or she encountered, where this information lead to successful "goal conversion," such as buying a product or, in an education context, learning a piece of information, and where the information lead to confusion or exiting a given site. Library organizations are now beginning to understanding that the true power of the internet for learning is not simply wide-scale (and often one-way) distribution of information, but getting ever closer to what is happening inside users' (learners' and customers') brains.

The recognition of the increasingly participatory nature of information services can also be seen in the rise of social network sites mentioned earlier, where the information service is little more than an infrastructure for user-contributed conversations and artifacts. Such services are only the purest example of a trend finding its way into a large number of web sites: users contributing to the ongoing conversation about an artifact (such as a book listed on Amazon), fact (such as an entry into Wikipedia), place (such as Flickr communities devoted to a given city), or just about any topic. In much the same way traditional tool developers feel an increasing pressure for community input, content providers are feeling an equal pressure for community input on their content. Part of this pressure comes from users who see participation as a crucial part of accessing the credibility of these artifacts, facts, and topics. 
The advent of services that allow greater user involvement such as blogs, social Credibility on the networks, recommender systems, and commenting have led to increased demand by users for greater involvement in services of all types. Returning to the author's definition of credibility, key components are trust and expertise; in essence, can one trust a person, and does that person know what they talking about? Increasingly users are looking to user-submitted comments, editorial reviews, and open conversations on a given topic, artifact, or idea to determine trust and expertise. And, in many cases where sites do not provide these functions, the community takes advantage of the open nature of the internet to create their own. This has led to the rise of an entire class of network destinations known as "protest sites." These sites are devoted to user discontent with a given institution, person, brand, or product. In the physical world, users might be limited to complaints to the organization, picketing, or reliance on third parties such as better business bureaus, whereas online users can seek out and build entire communities of discontented users regardless of location[1](Jenkins, 2003). Moreover, the newly-formed user community gains strength in numbers. Users new to the brand or item can now easily find such sites, allowing them to incorporate the dissenting views, as well as the official information, when making a credibility decision.

This style of grassroots organization has quickly spread from the consumer to the political arena. With an open network opposing voices that challenge the credibility of some given "official" information have equal access to the network and, at times, equal weight to official information outlets and forums (for a discussion of these types of sites as "Second Order Commonalities" and the inclusion of these "unauthorized messages, and, nonauthenticated links... within individuals' communication network" see Bimber et al., 2005, p. 372). Of course, this is not a perfect solution as the web also provides ample opportunity for false information to be put on the web. There are already ample examples of marketing firms "astroturfing," or setting up seemingly grassroots sites that actually promote products or approaches (Wikipedia, 2006). Certainly, users can put up false information, either intentionally or unintentionally, on protest sites. The result is that it becomes harder to determine the credibility of any one piece of information. False information also increases pressure on a given information service to provide opportunities for community feedback, in essence inviting protestors and commenters into a controlled space where an organization can at least respond to counter information.

This pressure for a voice can be expected to result in more opportunities for discussion and conversation in existing and new forms of digital media. It is not surprising that the walls between information seeking, learning and communicating are breaking down. Where once users would e-mail (or instant message) in one application, and search the web in another, they are now doing both simultaneously. This is not a simple matter of convenience, but rather is based on knowledge acquisition through conversation. Users are looking to talk in order to better evaluate what they find and synthesize this into actionable knowledge. It can also be expected that the trend of tracking users' conversations online will continue and will be enhanced. Library systems may well develop into conversational retrieval tools that link information by how others have used such information in their conversations. Just like libraries used to produce pathfinders and annotated bibliographies, users will soon be able to find a piece of information, such as a web site, and follow that information to all of the other public information used in a given conversation. Such a holistic context 


\section{JDOC 64,5}

678 will allow users to make credibility determinations not on a single item, but in the full context in which it sits. Digg.com (http://digg.com/) provides an excellent present-day example. When a Digg.com user finds an interesting news story on the web, they can mark it, allowing other Digg users to not only view the site, but also discuss it in an online forum; in essence taking the interest of one user and comparing it to a group's. Certainly, libraries will feel this pressure to participate. Online catalogs that are little more than inventory systems are already under fire to change. Lankes et al. (2007), for example, have applied the concepts of conversation theory and participation directly to libraries.

\section{Shifting credibility from authority to reliability}

As the pressure for participation in the infrastructure and applications of digital networks demonstrated the utility of participation and its impact on credibility, so the pressure was also seen in content and information services. In this section, the openness comes right to the user, and specifically how the power of choice is shifting models of credibility from traditional authorities to what will be called a "reliability approach" where the user determines credibility by synthesizing multiple sources of credibility judgments. Both the need for this synthesis approach and the richer set of resources to be synthesized are a product of pressure for participation.

\section{Authority}

Traditional approaches to credibility strongly emphasize authority. The author here defines "authority" as a trusted source used in place of a given individual's credibility decisions, or, as the Oxford English Dictionary (1989) defines it "derived or delegated power; conferred right or title; authorization". That trusted source is used to vouch for some given piece of information. A person may have many such authority sources, and may himself or herself serve as an authority in many different settings. The process of becoming or choosing an authority is a process of developing trust, and, arguably, seeking coherence and consistency in the authority.

Some have looked at the internet and claimed that authority is dead. Examples are plentiful, but a few sites and tools stand out in their arguments. Some have said Wikipedia (http://en.wikipedia.org/wiki/Main_Page) and group editing has become at least as authoritative (Chesney, 2006; Giles, 2005) as the traditional method for producing encyclopedias, it not more so (Stadler and Hirsh, 2002; Weiss, 2005). Others feel that blogging will also supersede (Johnson and Kaye, 2004) or definitely parallel (Haas, 2005) the authority of traditional news outlets. There are indeed a number of way in which traditional means of authority have been supplanted by open, flat structures for information creation and credentialing. However, to call this tantamount to the death of authority is, at best, an imprecise use of terminology. This new paradigm is not without authority, but it does require more sophisticated methodologies for evaluating it (McGunines et al., 2006; Nikolaos et al., 2006). While alternative views may not have been as celebrated or accessible as they are currently, history is replete with waves of centralization and decentralization of authority. The dramatic increase in information self-sufficiency has simply led to celebrating the large-scale nature of this decentralization.

Beyond this historical view, many communities are using the term authority as a single concept. That is, authority is hierarchical and centralized. It might be more 
precise to use the terms "authoritarian" and "authoritative." Authoritarian is defined as the enforcement of an authority, in essence the removal of choice by force of law, policy, structure, or some other means. Authoritative, on the other hand, is the perception of trust and expertise. The former is active and enforced, the latter is earned. Wikipedia is more likely to be the death of an authoritarian view that encyclopedias only come from Briticana, Groliers, or other large publishing houses, than it is to be the death of authority per se (Bryant et al., 2005).

The problem of determining the credibility of internet-based information is not a crisis of authority, but rather a crisis of choice. There are simply more choices in whom to trust, and market forces have not come into play to limit choices. While this is true for virtually all media venues to some degree, the scale of choice on the internet make the internet particularly affected by shifts in authority.

Libraries have been wrestling with this issue of shifting modes of authority and the internet since the early $1990 \mathrm{~s}$. Many in the library community have reacted to the overwhelming number and variety of information choices available to their clients via the internet by adopting an authoritarian view that the library is where to get good, accurate, and credible information, while the open internet is filled with bad and wrong information. One famed tag line of the time was "information on the internet is free, but you get what you pay for." Many want the library to become a preferred provider of information. Yet, the concept of "preferred" only works in an authoritarian view when there is someone who can make others prefer or select something over something else.

This resistance to the democratization of authority among librarians is ironic because there are few professions better suited to the authoritative world of the internet than librarians. They have a culture of open and free expression and access to ideas. They are generalists who move agilely across different topical domains. They are skilled at searching out information, and locating potential biases (and uses) in information. Their enterprises (i.e. libraries) have little invested in the production of information, and much invested in the consumption of information products from a wide variety of sources. Further, librarians already have a reputation as authoritative, not authoritarian.

It should also be noted that this resistance among some in the library community is far from universal. Nor is it limited to librarians. Teachers, college professors, and indeed just about any intermediary in information have had to wrestle with the new environment of plurality in authority. For some areas of the economy, the effects have been drastic. For example, the travel industry has been rocked by the growth in online bookings (Law et al., 2004; Wynne et al., 2001). While people may not be buying houses online, they are definitely using internet real estate listing services to even the marketplace (Littlefield et al., 2000; Palm and Danis, 2002). Perhaps, one of the most striking examples of the role of authority can be seen in the insurance industry. As Levitt and Dubner (2005) outline in their book, Freakonomics, the simple act of allowing consumers to directly compare term life insurance rates from different organizations over the internet instead of depending on the authority of a life insurance salesman lead to the cost of buying term life insurance in this nation dropping by $\$ 1$ billion. Interestingly, in this case the concept of an authority in a field (an insurance agent) was actually used to mask truly credible information.

It is not that the concept of multiple authorities did not exist before the internet, rather the cost in terms of time, money, and even reputation to seek out a multitude of authorities was too high. With the internet and other digital media the range of

\section{Credibility on the internet}

679 


\section{JDOC 64,5}

\section{0}

possible authorities has become extremely wide, and what's more, a consequence of the culture of information self-sufficiency is leading one-time consumers of authority to become authorities themselves. Before the internet, a user might have to rely on his or her local television news or newspaper to predict the weather. Now, he or she can go to the Weather Channel, Accuweather, or even the National Oceanic \& Atmospheric Administration for that information. They can, through whatever means, decide from a much wider pool who and what they will deem credible.

Not only do users have more sources to choose from, but now they can also directly access weather data from a variety of satellites and radar installations (including home-based weather stations), avoiding traditional authority sources to become authorities themselves. Through this direct access to source data a person can train themselves, formally or informally, until they feel they have sufficient expertise and trustworthiness to credibly interpret the information. Once the user takes it upon himself or herself to become an authority by directly evaluating and synthesizing often raw information, authority ends, and "reliability" becomes the predominant form of credibility assessment.

\section{Reliability}

Reliability commonly refers to something or someone who is perceived as dependable and consistent in quality. If you have a reliable car, it is one that runs well over time. Reliability to the scientist has a specific and limited meaning. Reliability is simply the consistency of data. If a thing (e.g. a fact, substance, or phenomenon) is subjected to the same treatment (e.g. questions, experiments, or applications) does it yield the same result? If an authority approach was as simple as believing that a given news anchor will give a credible answer, then switching from news station to news station looking for commonalities in the same story is a reliability approach.

Reliability approaches to credibility can be seen in the physical world. The fact that a person's signature is seen as a marker of credibility in legal settings is the belief that a person signs his or her name the same in a reliable fashion. Reliability is also seen as the cornerstone of good journalism where reporters must confirm information with a second source.

These two approaches, authority and reliability, are often used in conjunction in both the physical world and the digital world. In the aftermath of Hurricane Katrina in New Orleans in 2005, many residents turned to chat rooms and community-run web sites to resolve contradictory and often false information coming from traditional channels and sources (including the federal government and mass media). Local web sites, such as NOLA.com, allowed communities to come together and share information. Users were able to hear from multiple sources, including residents, and to get a more accurate, complete, and thus credible picture of the situation in the neighborhoods. Users who provided the most consistently accurate information became authorities.

The two concepts of authority and reliability do not have a co-equal status, however. Of the two, reliability is a much more powerful concept, in that reliability is one path to becoming an authority, and lack of reliability can destroy one's authority. Certainly, there are multiple means to becoming an authority. One simple means is that an agent is the only source for a type of information. If you want to know what's next for Apple, Inc., there may be a lot of experts who will venture an educated guess, but only Apple can say for sure. Hence, Apple is an, indeed, the authority. 
In the library world, libraries have come together to invest the power of authority in a given institution. For example, the Library of Congress keeps a file of book authors' names, birth and death information. When citing an author (or including them in a library record) someone can consult these authority files for proper spelling, aliases, and confirmation of an author's identity. This can be thought of as authority by consent, where all parties in a situation or context agree upon who will be the authority - that is, who will provide the unquestioned information.

Perhaps, the most common way to become an authority, however, is through reliability. If someone consistently gives out accurate (and testable) information in the absence of countervailing factors, they are seen as an authority (for a greatly expanded discussion of attributes of authority and these countervailing factors see de George, 1985). Experts are not simply people with the most experience, but people who have the longest track record in using their experience successfully. The true power of reliability, however, is not only in its ability to create authority, but also to destroy it as well. While the necessary degree of reliable performance for authority status varies across contexts (e.g. a soccer player who scores a goal every two matches is considered outstanding, even though he fails to score in half of his appearances, but a mathematician would not be considered an expert if she got math answers right only half of the time), it is clear that an agent giving out unreliable information over time will result in the loss of their authority status and, by extension, credibility.

Authority and reliability also have halo effects, meaning that a person can be seen as an authority in one area, may be presumed to be an authority in other domains as well without proven performance. This can be seen in celebrity endorsements for example. One could argue that librarians very much enjoy this halo effect. Likewise, unreliable performance in one area can cast doubt on performance in other areas. Like an accountant that cheats at Monopoly, or a minister that cheats on his wife, loss of credibility in one area can cast suspicion on other domains of authority. These halo effects become even more pronounced in the digital environment when the information about and from an agent (person and organization process) can be more voluminous and diverse than on offline environments.

Ultimately, reliability and authority can be seen as opposite ends on a spectrum of credibility approaches. In authority, as mentioned, pre-existing agreements are in place and assumed: the conversation is over. In reliability, by contrast, the conversation is open and ongoing. Users are seeking out information and other people to come to a credibility judgment. Since digital networks bring to the user such an overwhelming amount of information and people to engage with in arriving at a credibility judgment, the tools they use must all incorporate some ability to participate, or engage in a conversation with people and sources. This explains the growing pressure on tools builders and information services to be more open and more participatory. The information self-sufficient user requires constant conversation. Thus, the tools built for users to find and use credible information must be increasingly participatory and facilitate reliability approaches.

\section{Conclusion}

This paper described the growth of information self-sufficiency and the underlying paradox where users are simultaneously more responsible for information decisions, while also more dependent on the providers of that information and the tools used to manipulate
Credibility on the internet

681 
JDOC 64,5

682 that information. It presented a model that posited knowledge is gained through conversation, and that digital networks and tools must address this underlying reality. It discussed how the internet and digital networks that allow for community participation in the construction of the underlying network and infrastructure have become the predominant model for existing and future digital media. It showed how this need for participating and involvement has impacted information services, and finally the users themselves in terms of how they define and assess credible information.

A primary aim of the paper has been to highlight trends that will most likely endure and will continue and/or expand in future digital media, and to show how users are both effecting and being affected by these trends. Large-scale digital networks have extended users' ability to build their own networks of credibility. They have also allowed users to participate in the networks as equals to all other sectors of society, in essence elevating their own personal credibility in certain domains. The next widely adopted application on the internet is as likely to come from a teenager as from a Fortune 500 company. However, this new reality has serious implications for society as a whole and libraries in particular.

In order to be an intelligent part of the ongoing conversations on the internet and shape it, users and librarians alike must be fluent in both the tools that facilitate the conversation and be aware of the credibility dimensions embedded in the tools themselves. The omnipresent nature of the digital environment is necessitating more technical fluency and greater explicit consideration of credibility and technology for information professionals and information organizations.

Users in the internet community have now come to expect involvement in all aspects of information in the network. Libraries, business, governments, and all other organizations must change to accommodate this expectation. If not, users will migrate their attention to venues that allow for conversation and debate of information, or create their own. This is perhaps the most important implication for users from the increasing requirement for participation on the network. Individuals can and will increasingly expect to shape their information domain, and define credible information on their own terms. Any system that seeks to either impose an authority view of credibility, or that seeks to change behavior must now do it with the understanding that users can simply bypass these attempts and create counter structures. Furthermore, these alternative credibility structures can have a global reach and build communities of like minds across divisions of geography, race, gender, age, and other demarcations.

\section{Note}

1. Examples include: Stony Brook Sucks (www.portjeffweb.com/stonybrook/view.asp) and RateMyTeacher.com (www.ratemyteachers.com/).

\section{References}

Abend, J. (1999), "Lands' end uses internet to expand sales, personalize customer service", Bobbin. FindArticles.com, www.findarticles.com/p/articles/mi_m3638/is_10_40/ ai_55609089 (accessed December 15, 2006).

Becker, L. (2002), "Self-service web applications: less cost, more value", available at: www.adaptivepath.com/publications/essays/archives/000063.php (accessed November 15, 2006). 
Bimber, B., Flanagin, A.J. and Stohl, C. (2005), "Reconceptualizing collective action in the contemporary media environment", Communication Theory, Vol. 15, pp. 365-88.

Bryant, S.L., Forte, A. and Bruckman, A. (2005), "Becoming Wikipedian: transformation of participation in a collaborative online encyclopedia", Proceedings of the 2005 International ACM SIGGROUP Conference on Supporting Group Work, Sanibel Island, FL, USA, pp. 1-10.

Chesney, T. (2006), "An empirical examination of Wikipdeia's credibility”, First Monday, Vol. 11 No. 11, available at: www.firstmonday.org/issues/issue11_11/chesney/index.html (accessed January 4, 2006).

Choo, J. and Roy, S. (2004), "Impact of search engines on page popularity", International World Wide Web Conference: Proceedings of the 13th International Conference on World Wide Web, ACM Press, New York, NY, pp. 20-9.

de George, R.T. (1985), The Nature and Limits of Authority, University Press of Kansas, Lawrence, KS.

Dg.o (2006), "The National Science Foundation's digital government research program", available at: www.digitalgovernment.org/ (accessed December 15, 2006).

Federal Election Commission (2006), Help America Vote Act of 2002: Public Law 107-252, available at: www.fec.gov/hava/hava.htm (accessed November 15, 2006).

Flannigan, A. and Metzger, M. (2007), "Introduction, in MacArthur 2007”, in Metzger, M. and Flanagin, A. (Eds), Digital Media, Youth, and Credibility, MacArthur Foundation Series on Digital Media and Learning, Chicago, IL.

Fogg, B.J. (2002), Persuasive Technology: Using Computers to Change What We Think and Do, Morgan Kaufman, New York, NY.

Fogg, B.J., Soohoo, C., Danielson, D.R., Marable, L., Stanford, J. and Tauber, E.R. (2003), "How do users evaluate the credibility of web sites? A study with over 2,500 participants", Proceedings of the 2003 Conference on Designing for User Experiences, San Francisco, CA, USA, pp. 1-15.

Fogg, B.J., Marshall, J., Laraki, O., Osipovich, A., Varma, C., Fang, N., Paul, J., Rangnekar, A., Shon, J., Swani, P. and Treinen, M. (2001), "What makes web sites credible? A report on a large quantitative study", Proceedings of the SIGCHI Conference on Human Factors in Computing Systems, Seattle, Washington, USA, March 31-April 4, pp. 61-8.

Fogg, B.J., Marshal, J., Osipovich, A., Varma, C., Laraki, O., Fang, N., Paul, J., Rangnekar, A., Shon, J., Swani, P. and Treinen, M. (2000), "Elements that affect web credibility: early results from a self-report study", Proceedings of ACM CHI 'OO Extended Abstracts on Human Factors in Computing Systems, The Hague, The Netherlands, pp. 287-8.

Fott, G. (2006), “Adobe Photoshop CS3 Beta”, available at: www.pcmag.com/article2/ 0,1895,2074376,00.asp (accessed January 6, 2007).

Friedman, B., Kahn, P.H. Jr and Borning, A. (2006), "Value sensitive design and information systems", in Zhang, P. and Galletta, D. (Eds), Human-computer Interaction in Management Information Systems: Foundations, M.E. Sharpe, London, pp. 348-72.

Giles, J. (2005), “Internet encyclopedias go head to head”, Nature, Vol. 438, pp. 900-1.

Grants.gov. (2006), available at: www.grants.gov/ (accessed November 25, 2006).

Haas, T. (2005), "From 'public journalism' to the 'public's journalism'? Rhetoric and the reality in the discourse on weblogs", Journalism Studies, Vol. 6 No. 3, pp. 387-96.

Halpern, D.F. (2003), Thought \& Knowledge: An Introduction to Critical Thinking, 4th ed., Lawrence Erlbaum Associates, Mahwah, NJ.

\section{Credibility on the internet}

683 
JDOC 64,5

\section{4}

Ivory, M.Y. and Megraw, R. (2005), "Evolution of website design patterns", ACM Transactions on Information Systems, Vol. 23 No. 4, pp. 463-97.

Jenkins, P.S. (2003), "Leafleting and picketing on the 'Cydewalk' - four models of the role of the internet in labour disputes", UCLA Journal of Law and Technology, Vol. 7 No. 1.

Johnson, T.J. and Kaye, B.K. (2004), "Wag the blog: how reliance on traditional media and the internet influence credibility perceptions of weblogs among blog users", Journalism and Mass Communication Quarterly, Vol. 81 No. 3, pp. 622-42.

Lankes, R.D. (1999), Building and Maintaining Internet Information Services: K-12 Digital Reference Services, ERIC Clearinghouse on Information \& Technology, Syracuse, NY.

Lankes, R.D., Silverstein, J. and Nicolson, S. (2007), "Participatory networks: the library as conversation”, available at: http://iis.syr.edu/projects/PNOpen/ (accessed March 10, 2007).

Law, R., Leung, K. and Wong, R.J. (2004), "The impact of the internet on travel agencies", International Journal of Contemporary Hospitality Management, Vol. 16 No. 2, pp. 100-7.

Levitt, S. and Dubner, S. (2005), Freakonomics: A Rogue Economist Explores the Hidden Side of Everything, William Morrow, New York, NY.

Littlefield, J.E., Bao, Y. and Cook, D.L. (2000), "Internet real estate information: are home purchasers paying attention to it?”, Journal of Consumer Marketing, Vol. 17 No. 7, pp. 575-90.

McGunines, D.L., Zeng, H., da Silva, P.P., Ding, L., Narayanan, D. and Bhaowal, M. (2006), "Investigations into trust for collaborative information repositories: a Wikipedia case study", Proceedings of the Workshop on Models of Trust for the Web. WWW2006, Edinburgh, UK, May 22-26, available at: http://ebiquity.umbc.edu/_file_directory_/ papers/274.pdf (accessed January 4, 2007).

Madden, M. (2006), "Internet penetration and impact", Pew Internet \& American Life Project, available at: www.pewinternet.org/PPF/r/182/report_display.asp (accessed November 15, 2006).

Madden, M. and Fox, S. (2006), "Riding the waves of 'web 2.0': more than a buzzword, but still not easily defined”, Pew Internet Project, available at: www.pewinternet.org/pdfs/PIP_Web_2. 0.pdf (accessed December 12, 2007).

Metzger, M.J., Flannagin, A.J. and Zwarun, L. (2003a), "College student web use, perceptions of information credibility, and verification behavior", Computers \& Education, Vol. 41, pp. 271-90.

Metzger, M.J., Flanagin, A.J., Eyal, K., Lemus, D. and McCann, R.M. (2003b), "Bringing the concept of credibility for the 21st century: integrating perspectives on source, message, and media credibility in the contemporary media environment", in Kalbfleish, P. (Ed.), Communication Yearbook, Vol. 27, Erlbaum, Mahwah, NJ, pp. 293-335.

Meuter, M.L., Ostrom, A.L., Roundtree, R.I. and Bitner, M. (2000), "Self-service technologies: understanding customer satisfaction with technology-based service encounters", Journal of Marketing, Vol. 64, pp. 50-64.

Miteko, T. (2006), "Driving value from every online customer interaction: the power of intent-driven personalization”, Customer Inter@ction Solutions., Vol. 24 No. 8, pp. 38-41.

Mowshowitz, A. and Kawaguchi, A. (2002), "The consumer side of search: bias on the web", Communications of the ACM, Vol. 45 No. 9, pp. 56-60.

Nikolaos, T.K., Poulos, M. and Bokos, G. (2006), "Evaluating authoritative sources using social networks: an insight from Wikipedia", Online Information Review, Vol. 30 No. 3, pp. 252-62. 
Oxford English Dictionary (1989), "Entry on authority", 2nd ed., available at: http://dictionary. oed.com/cgi/entry/50015071?query_type $=$ word\&queryword $=$ authority\&first $=1 \&$ max_to_show $=10 \&$ sort_type $=$ alpha\&result_place $=1 \&$ search_id $=$ gPnp- $21 \mathrm{~m}$ Q0y-3202\&hilite $=50015071$ (accessed December 29, 2006).

Palm, R. and Danis, M. (2002), "The internet and home purchase", Tijdschrift voor Economische en Sociale Geografie, Vol. 93 No. 5, pp. 537-47.

Pask, G. (1976), Conversation Theory: Applications in Education and Epistemology, Elsevier, New York, NY.

PEACEFIRE (2006), available at: www.peacefire.org/ (accessed December 29, 2006).

Raymond, E. (2001), Cathedral and the Bazaar: Musings on Linux and Open Source by an Accidental Revolutionary, O'Reilly Media, Sebastopol, CA.

Rice, K.L. (2006), "A comprehensive look at distance education in the K-12 context”, Journal of Research on Technology in Education, Vol. 38 No. 4, pp. 425-48.

Silverstein, J. (1997), "Information technology and commerce: attributes of emerging online business", unpublished doctoral dissertation, Syracuse University, Syracuse, NY.

Stadler, F. and Hirsh, J. (2002), "Open source intelligence”, First Monday, Vol. 7 No. 6, available at: http://firstmonday.org/issues/issue7_6/stalder/index.html (accessed January 4, 2007).

van Riel, A., Liljander, V. and Jurriens, P. (2001), "Exploring consumer evaluations of e-services: a portal site", International Journal of Service Industry Management, Vol. 12 No. 4, pp. 359-77.

Walther, J.B., Wang, Z. and Loh, T. (2004), "The effect of top-level domains and advertisements on health web site credibility", Journal of Medical Internet Research, Vol. 6 No. 3, e24, available at: www.jmir.org/2004/3/e24/ (accessed January 3, 2006).

Wathen, C.N. and Burkell, J. (2002), "Believe it or not: factors influencing credibility on the web", Journal of the American Society for Information Science and Technology, Vol. 53 No. 2, pp. 134-44.

Weiss, A. (2005), “The power of collective intelligence”, NetWorker, Vol. 9 No. 3, pp. 16-23.

Wikipedia (2006), Astroturfing, available at: http://en.wikipedia.org/wiki/Astroturfing (accessed December 29, 2006).

Wikipedia (2007), "Broadband internet access", available at: http://en.wikipedia.org/wiki/ Broadband_Internet_access (accessed on August 5, 2007).

Wray, R. and Milmo, D. (2006), “AOL tries to survive by going free”, available at: http://business. guardian.co.uk/story/0,1835908,00.html (accessed January 2, 2007).

Wynne, C., Berthon, P., Pitt, L., Ewing, M. and Napoli, J. (2001), "The impact of the internet on the distribution value chain: the case of the South African tourism industry", International Marketing Review, Vol. 18 No. 4, pp. 420-31.

Zeldman, J. (2003), Designing with Web Standards, New Riders Press, Thousands Oaks, CA.

\section{Further reading}

Brett, J.D. and Egley, R.J. (2006), "Looking through different lenses: teachers' and administrators' views of accountability", Phi Delta Kappen, Vol. 87 No. 10, pp. 767-71.

Davies, C., Hayward, G. and Lukman, L. (2006), "14-19 and digital technologies: a review of research and projects", available at: www.futurelab.org.uk/download/pdfs/research/ lit_reviews/futurelab_review_13.pdf (accessed December 29, 2006).

Florida Virtual School (2006), available at: www.flvs.net/educators/fact_sheet.php (accessed December 28, 2006). 
JDOC

64,5

686
(The) Internet Gopher (2006), "History of the Gopher Protocol", available at: www.codeghost. com/gopher_history.html (accessed December 29, 2006).

Lenhart, R. and Lewis, O. (2001), “Teenage life online: the rise of the instant-message generation and the internet's impact on friendships and family relationships", available at: www. pewinternet.org/PPF/r/36/report_display.asp (accessed December 15, 2006).

Lenhart, A., Simon, M. and Graziano, M. (2001), "The internet and education: findings of the pew internet \& American life project", available at: www.pewinternet.org/PPF/r/39/ report_display.asp (accessed December 28, 2006).

Lowe, C. (2005), "Yale University's PACE Research Center and the Big6 $6^{\mathrm{TM}}$ ", available at: http:// big6.com/showarticle.php?id = 459 (accessed November 15, 2006).

MacArthur Foundation (2006) MacSeries Volumes, available at: www.digitallearning.macfound. org/site/c.enJLKQN1FiG/b.2029271/k.E73F/MacSeries.htm (accessed December 15, 2006).

Market Wire (2006), "US teens graduate from choosing IM buddy icons to creating elaborate social networking profiles", According to Nielsen//NetRatings www.marketwire.com/mw/ release_html_b1?release_id $=171656$ (accessed December 28, 2006).

\section{Corresponding author}

R. David Lankes can be contacted at: rdlankes@iis.syr.edu 